\title{
Proliferation and metastatic potential of endometrial cancer cells in response to metformin treatment in a high versus normal glucose environment
}

\author{
AMANDA DE BARROS MACHADO ${ }^{1-3}$, VANIA DOS REIS ${ }^{1,2}$, SEBASTIAN WEBER $^{3}$, \\ JULIA JAUCKUS ${ }^{3}$, ILMA SIMONI BRUM ${ }^{1,2}$, HELENA VON EYE CORLETA ${ }^{1,2}$, \\ THOMAS STROWITZKI ${ }^{3}$, EDISON CAPP ${ }^{1-3}$ and ARIANE GERMEYER ${ }^{3}$
}

\begin{abstract}
${ }^{1}$ Laboratory of Molecular Endocrine Biology and Tumor Biology, Department of Physiology, Institute of Basic Sciences of Health, Federal University of Rio Grande do Sul; ${ }^{2}$ Laboratory of Molecular Obstetrics and Gynecology, Experimental Research Center, Department of Obstetrics and Gynecology, Hospital de Clinicas de Porto Alegre, Federal University of Rio Grande do Sul, Porto Alegre, Rio Grande do Sul 90050-170, Brazil; ${ }^{3}$ Department of Gynecological Endocrinology and Reproductive Medicine, University Hospital Heidelberg, D-69120 Heidelberg, Germany
\end{abstract}

Received February 3, 2016; Accepted July 22, 2016

DOI: $10.3892 / \mathrm{ol} .2016 .5041$

\begin{abstract}
In order to improve our understanding of the potential preventive and therapeutic role of metformin, the present study aimed to investigate the capability of low-dose metformin in the efficient inhibition of cancer development and the reduction of the metastasis of endometrial adenocarcinoma type I and primary endometrial epithelial cells (eEPs), with the drug acting as a treatment in a hyperinsulinemic environment exposed to high and normal glucose conditions. The Ishikawa endometrial adenocarcinoma cell line and primary eEPs were exposed to an environment with high $(17 \mathrm{mM})$ or normal glucose $(5 \mathrm{mM})$ and treated with insulin, low-dose metformin $(0.1 \mathrm{mM})$ or a combined treatment. Metastatic potential was assessed by migration and invasion assays, and relative cell proliferation was determined. Metformin at a low dose potently inhibited the insulin action, decreasing the ability of the endometrial cancer (EC) cell line to migrate and invade in a high and normal glucose environment, and decreasing the migration ability of the primary eEPs. In the EC cell line, the insulin treatment increased the proliferation, without any subsequent reduction of proliferation by the addition of $0.1 \mathrm{mM}$ metformin; however, relative cell proliferation sensitivity to metformin was observed in the range between 1 and $5 \mathrm{mM}$ regardless of the glucose concentration present. Overall, metformin at $0.1 \mathrm{mM}$ is not efficient enough to decrease the
\end{abstract}

Correspondence to: Ms. Amanda de Barros Machado, Department of Gynecological Endocrinology and Reproductive Medicine, University Hospital Heidelberg, Building 440, D-69120 Heidelberg, Germany

E-mail: amandabarrosm@yahoo.com.br

Key words: endometrial cancer, metformin, hyperinsulinemia, glucose, metastasis, cancer development proliferation in an EC cell line. However, at this concentration, metformin can inhibit the insulin action in endometrial epithelial cancer cells, demonstrating an anti-metastatic effect in high and normal glucose environments.

\section{Introduction}

Endometrial cancer (EC) is one of the most common gynecological malignancies worldwide (1) and is classified into estrogen-dependent type I and estrogen-independent type II forms. The type I form is the most common, accounting for $75-85 \%$ of all cases of EC (2). Unopposed estrogen has been shown to increase the risk of EC development, as estrogens stimulate endometrial cell proliferation and inhibit apoptosis (3). Additionally, diseases associated with insulin resistance, such as obesity, type II diabetes mellitus and polycystic ovary syndrome (PCOS), are considered significant risk factors for the development and progression of type I EC (4-6). Insulin resistance is a condition in which target tissues have decreased sensitivity to insulin, and blood insulin levels consequently increase to maintain normal glucose levels. The chronic hyperinsulinemic state has been found to exert direct and indirect effects that contribute to EC development (7). A large body of evidence has suggested that women with diabetes possess a stronger association with neoplastic processes (5), and furthermore, diabetic patients with cancer experience increased mortality compared with normoglycemic individuals (8). Finally, a meta-analysis study has shown that women with diabetes have a two-fold risk for EC (9). Insulin resistance appears to play a central role in endometrial carcinogenesis. Therefore, treatment with insulin-sensitizing agents that act through reducing insulin levels could offer a general approach to prevent the development of cancer and reduce metastasis $(10,11)$.

Metformin, an anti-hyperglycemic and insulin sensitizing agent, is the most commonly used drug for treating type II diabetes mellitus, as well as off-label insulin resistance 
(as observed in women with PCOS) (12). In recent years, numerous studies have indicated that metformin could be effective as a cancer therapy, along with its traditional role in treating diabetes (13-15). Metformin use can prevent malignant transformation indirectly via systemic changes (improving hyperglycemia, hyperlipidemia and hyperinsulinemia) and via direct effects, such as suppression of mammalian target of rapamycin via 5' adenosine monophosphate-activated protein kinase activation, leading to reduced protein synthesis and cell proliferation $(16,17)$. A meta-analysis of 18 observational studies showed that metformin therapy is associated with an overall $27 \%$ reduction in the risk of developing any type of cancer in patients with type II diabetes (18). A retrospective study showed that metformin use is additionally associated with less recurrence and improved overall survival in EC patients; although, when recurrence took occurred, it was not delayed compared with that in the control (19). However, the majority of these previous studies possessed methodological weaknesses and/or insufficient data.Additionally, experimental studies revealed that metformin is an effective antiestrogenic agent, inhibiting cell proliferation and leading to growth arrest, as well as inducing apoptosis in EC (17,20-22). Furthermore, recent findings have suggested that metformin is important in suppressing the migration and invasion of cancer cells, which could prevent metastasis (23-25). However, in these studies metformin action was observed at high supra-pharmacological concentrations and without estradiol addition, an important factor in endometrial proliferative disorders.

The present study investigated the capability of low-dose metformin $(0.1 \mathrm{mM})$ to inhibit the development of cancer and reduce the metastatic potential of endometrial adenocarcinoma type I in vitro using the Ishikawa cell line in the high and normal glucose environments. Finally, the study evaluated the efficiency of low-dose metformin to prevent EC using normal uterine endometrial epithelial cells (eEPs) exposed to high glucose concentrations.

\section{Materials and methods}

Isolation and culture of primary eEPs. The primary eEPs were isolated from endometrial biopsies (between March and August 2015) taken from healthy, regularly cycling women (34.1 \pm 3.4 years old) undergoing laparoscopic surgery for benign reasons. Informed consent was obtained and the study protocol was approved by the the Clinical Hospital of Porto Alegre (Porto Alegre, Rio Grande do Sul, Brazil) and the University of Heidelberg (Heidelberg, Germany). Exclusion criteria were hormonal stimulation within the preceding 3 months, endocrinopathies, cancerous lesions and irregular menstrual bleeding. Human endometrial tissues were digested with collagenase type Ia (Gibco, Karlsruhe, Germany) for $2 \mathrm{~h}$. Thereafter, the cells were washed, centrifuged ( $800 \mathrm{x}$ g, room temperature) and separated using a $40-\mu \mathrm{m}$ filter. The stromal cells passed through the filter and the epithelial cells were retained. Epithelial cells were recovered from the filter by backwashing with Dulbecco's modified Eagle's medium (DMEM)/F12 (Gibco; Thermo Fisher Scientific Inc., Waltham, MA, USA).

Cell culture. The Ishikawa human endometrial adenocarcinoma cell line was purchased from Sigma-Aldrich (Merck
Millipore, Darmstadt, Germany; European Collection of Cell Culture authenticated). Ishikawa cells were grown in minimal essential medium (MEM; Sigma-Aldrich; Merck Millipore) supplemented with 5\% fetal bovine serum (FBS; HyClone; Thermo Fisher Scientific Inc.), $1 \%$ penicilin-streptomycin (Gibco; Thermo Fisher Scientific Inc.), 1\% non-essential amino acids (Sigma-Aldrich; Merck Millipore) and $5 \mu \mathrm{g} / \mathrm{ml}$ bovine insulin (Sigma-Aldrich; Merck Millipore), while the primary eEPs were maintained in DMEM/F12 supplemented with 5\% FBS and $1 \%$ penicillin-streptomycin at $37^{\circ} \mathrm{C}$ in a humidified atmosphere with $5 \% \mathrm{CO}_{2}$.

For the experiments in a high glucose environment, the cells were cultured in various conditions with DMEM/F12 medium containing $17 \mathrm{mM}$ glucose, and for the experiments in a normal glucose environment, the cells were cultured with MEM containing $5.5 \mathrm{mM}$ glucose. The media for all conditions were supplemented with $10^{-8} \mathrm{M}$ estradiol. The different conditions included: a) Control group, medium only; b) insulin group, medium plus $100 \mathrm{ng} / \mathrm{ml}$ insulin; c) metformin group, medium plus $0.1 \mathrm{mM}$ metformin; and d) insulin plus metformin group, medium plus $100 \mathrm{ng} / \mathrm{ml}$ insulin and $0.1 \mathrm{mM}$ metformin. All chemicals were purchased from Sigma-Aldrich (Merck Millipore).

Migration and invasion analysis. To assess the ability of cellular motility in the different conditions, Transwell filters (6.5 $\mathrm{mm}$ in diameter; $5-\mu \mathrm{m}$ pore size; Corning Inc., Corning, NY, USA) were used. The cells were harvested as aforementioned and suspended in serum-free medium. The Transwell filter was coated with $100 \mathrm{ml}$ medium for the migration assay or with $100 \mu$ l Matrigel (1:1 dilution; Corning Matrigel Growth Factor Reduced; Corning Inc.) for the invasion assay. Thereafter, the primary eEPs $\left(1 \times 10^{4}\right.$ in $\left.200 \mu \mathrm{l}\right)$ or Ishikawa cells $\left(2.5 \times 10^{5}\right.$ in $\left.200 \mu \mathrm{l}\right)$ were added with the individual treatment conditions into the Transwell chamber. Medium containing $5 \%$ FBS was added to the lower well, then the Transwells were incubated for $16 \mathrm{~h}$. Non-migrated/invading cells were removed with a cotton swab, and migrated/invading cells were fixed in $3.7 \%$ paraformaldehyde in phosphate-buffered saline, permeabilized with $100 \%$ methanol and stained with Giemsa. Cell migration/invasion, repeated five times, was quantified by blinded counting of the number of migrated/invaded cells in each insert in four different areas. Data are expressed as the percentage compared with the control group.

Cell proliferation assays. The CellTiter Glo Luminescent assay (Promega Corporation, Madison, WI, USA) was used to evaluate the relative cell proliferation of Ishikawa cells exposed to high and normal glucose conditions. The cells were seeded into 96-well plates at a density of 5,000 cells/well in $100 \mu \mathrm{l}$ drug-free medium overnight. The cells were then treated with the indicated treatment (control, insulin, metformin or insulin plus metformin) for $72 \mathrm{~h}$. After this period, the plates were equilibrated at room temperature for $30 \mathrm{~min}$, and $100 \mu \mathrm{l}$ of CellTiter Glo reagent was added in each well, mixed for $2 \mathrm{~min}$ and incubated at room temperature for $10 \mathrm{~min}$. The luminescence was detected by a Centro LB 960 Microplate Luminometer (Berthold Technologies GmbH and Co. KG, Bad Wildbad, Germany).

In order to evaluate the sensitivity of the epithelial carcinoma cells to varying doses of metformin in high and 

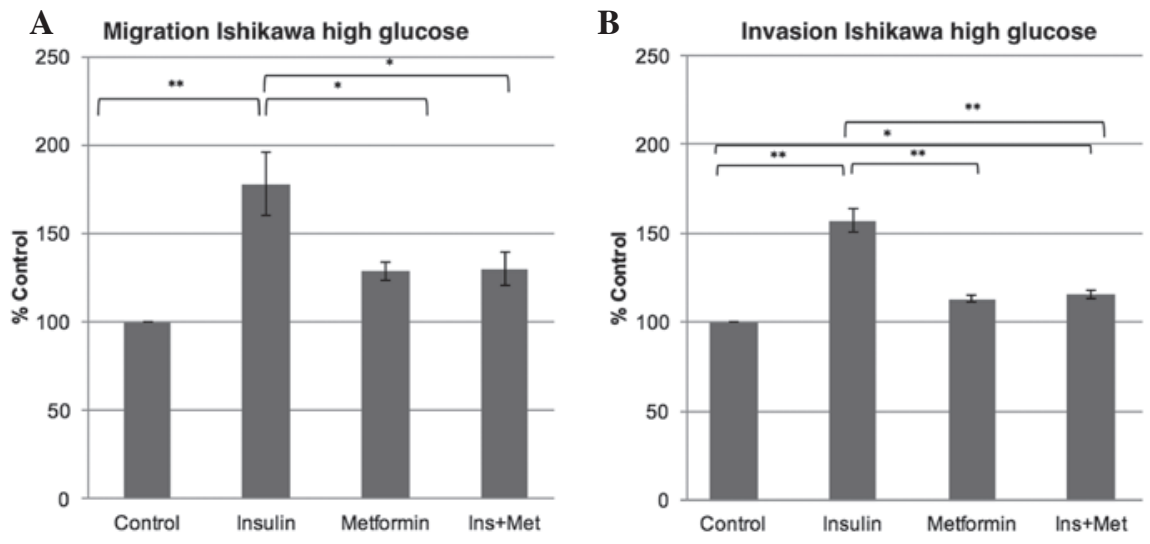

Figure 1. Migration and invasion of the Ishikawa cell line in a high glucose environment during $16 \mathrm{~h}$ of incubation. The insulin treatment increased the ability to migrate and invade. The metformin treatment was able to inhibit the insulin effect. (A) Migration assay in a high glucose environment; ${ }^{*} \mathrm{P}=0.023$ and ${ }^{* *} \mathrm{P}<0.001$. (B) Invasion assay in a high glucose environment; ${ }^{*} \mathrm{P}=0.030$ and ${ }^{* *} \mathrm{P}<0.001$. Mean \pm standard error of the mean. Ins, insulin; Met, metformin.
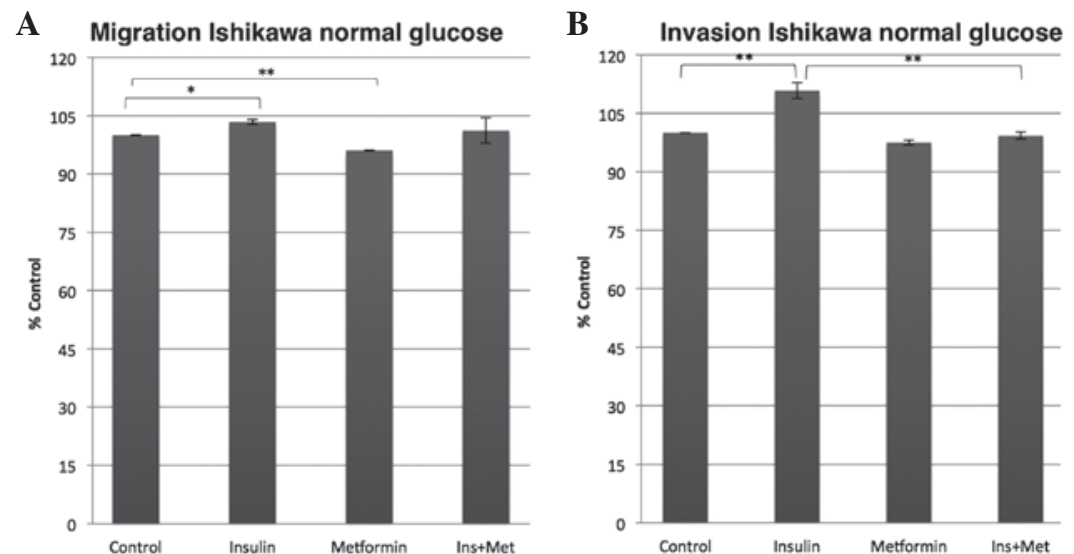

Figure 2. Migration and invasion of the Ishikawa cell line in a normal glucose environment during $16 \mathrm{~h}$ of incubation. The insulin treatment increased the ability to migrate and invade. The metformin treatment was able to inhibit the insulin effect. (A) Migration assay in a high glucose environment; " $\mathrm{P}=0.032$ and ${ }^{* *} \mathrm{P}=0.001$. (B) Invasion assay in a high glucose environment; ${ }^{* *} \mathrm{P}=0.006$. Mean \pm standard error of the mean. Ins, insulin; Met, metformin.

normal glucose conditions, the Ishikawa cells were seeded into 96-well plates at a density of 5,000 cells/well in $100 \mu \mathrm{l}$ drug-free medium overnight. The cells were then treated with increasing doses of metformin $(0,0.1,1$ and $5 \mathrm{mM})$ for $72 \mathrm{~h}$. A CellTiter Glo Luminescent assay was performed as aforementioned. The effect of the different treatments was calculated as a fold-change compared with the control group. Each experiment was performed in sextuplicate and repeated three times.

Statistical analysis. Quantitative data are represented as the mean \pm standard error of the mean of at least three independent experiments. SPSS version 23 (IBM SPPS, Armonk, NY, USA) was used to perform a one-way analysis of variance and Turkey's post-hoc test, a generalized estimating equation test or Student's t-test, as appropriate. $\mathrm{P}<0.05$ was considered to indicate a statistically significant difference.

\section{Results}

Low-dose metformin inhibits the insulin effect on the migration and invasion in the EC cell line. The present study examined the effect of a hyperinsulinemic environment with or without metformin treatment on the migration and invasion ability of Ishikawa cells when exposed to a high or normal glucose environment. In a high glucose environment, insulin exposure increased the migration by $77 \%(\mathrm{P}<0.001)$ and the invasion capability by $57 \%(\mathrm{P}<0.001)$ in the Ishikawa cells compared with the control. While metformin alone did not confer any change in the migration and invasion capabilities of the Ishikawa cells in a high glucose environment when compared with the control, the metformin co-treatment (insulin plus $0.1 \mathrm{mM}$ metformin) markedly attenuated the insulin effect, leading to a decrease in the migration ability by $47 \%(\mathrm{P}=0.023)$ and in the invasion ability by $42 \%$ $(\mathrm{P}<0.001)$, therefore reducing the insulin effect (Fig. 1). In the normal glucose environment, however, the insulin and the metformin effects were less dominant compared with those in the high glucose environment. While the insulin exposure of the Ishikawa cells only slightly increased the migration and invasion ability by $3 \%(\mathrm{P}=0.032)$ and $10 \%(\mathrm{P}=0.006)$, respectively, compared with the control, the metformin co-treatment almost completely abolished the insulin effect on the invasion potential, as the metformin co-treatment inhibited the insulin effect on the invasion ability to a control rate (Fig. 2). Metformin alone on the other hand significantly decreased the capability of the Ishikawa cells to migrate by 

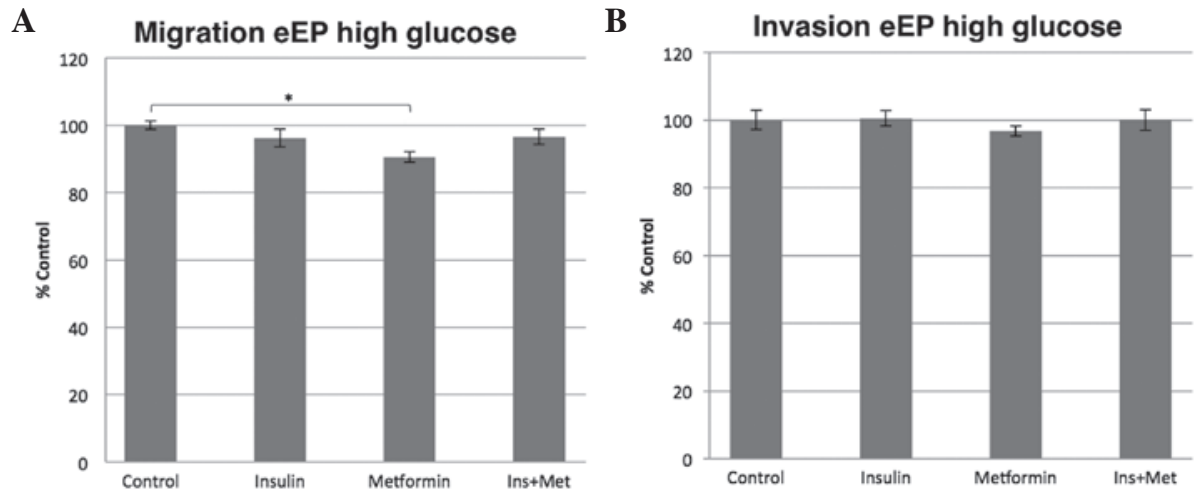

Figure 3. Migration and invasion of the primary eEPs in a high glucose environment during $16 \mathrm{~h}$ of incubation. The metformin treatment decreased the migration effect. (A) Migration assay in a high glucose environment. (B) Invasion assay in a high glucose environment. Mean \pm standard error of the mean. $\mathrm{P}<0.001$. eEPs, endometrial epithelial cells; Ins, insulin; Met, metformin.

A

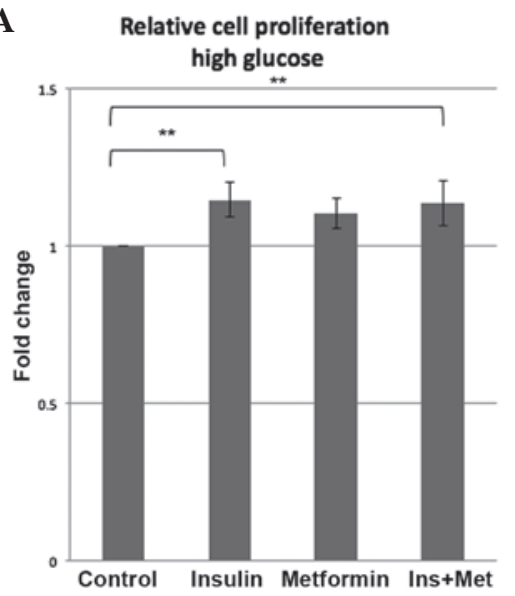

B

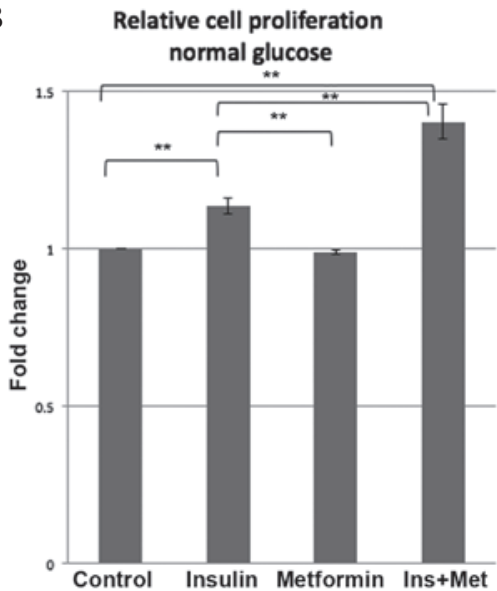

Figure 4. Relative cell proliferation of the Ishikawa cell line in a (A) high glucose and a (B) normal glucose environment. The insulin treatment increased the proliferation in the two glucose conditions and metformin at $0.1 \mathrm{mM}$ was not able to reduce the proliferation. Mean \pm standard error of the mean. ${ }^{* *} \mathrm{P}=0.05$. Ins, insulin; Met, metformin.

$4 \%(\mathrm{P}=0.001)$ and non-significantly decreased their ability to invade by $3 \%(\mathrm{P}=0.069)$ compared with the control.

Low-dose metformin is effective in primary eEPs. To investigate the efficiency of metformin treatment, the effect of metformin on normal eEPs was analyzed. When the primary eEPs were cultured in a high glucose environment, insulin alone or in combination with metformin did not change the migration or invasion potential after $16 \mathrm{~h}$. However, metformin alone inhibited the migration potential significantly by $10 \%$ $(\mathrm{P}<0.001)$ and the invasion capacity non-significantly by $4 \%$ $(\mathrm{P}=1.000)$ compared with the control (Fig. 3).

Low-dose metformin does not decrease the proliferation of the EC cell line. To determine if the glucose environment affects the proliferation potential of epithelial cancer cells, Ishikawa cells were treated using the four treatment conditions (control, insulin, metformin and insulin plus metformin) for $72 \mathrm{~h}$ in media containing high or normal glucose. As shown in Fig. 4, insulin treatment increased the proliferation of the Ishikawa cells by 1.15 -fold in the high glucose condition $(\mathrm{P}=0.029)$ and by 1.13 -fold in the normal glucose condition $(\mathrm{P}=0.003)$ compared to the control group. However, treatment with $0.1 \mathrm{mM}$ metformin did not have a significant effect on Ishikawa cell proliferation compared with the control group in the $72 \mathrm{~h}$, either in a high or normal glucose environment. Furthermore, in this treatment period, $0.1 \mathrm{mM}$ metformin in combination with insulin was not able to inhibit the stimulatory insulin effect on the proliferation potential in high glucose and even lead to an enhanced proliferation potential in the normal glucose condition compared with the control (1.40-fold; $\mathrm{P}<0.001)$.

Metformin decreases EC cell line proliferation in a dose-dependent manner. In order to test the sensitivity of the EC cell line to metformin at different concentrations in a high and normal glucose environment, the proliferation of Ishikawa cells treated with metformin $(0,0.1,1$ and $5 \mathrm{mM})$ in medium containing high and normal levels of glucose for $72 \mathrm{~h}$ was measured (Fig. 5). Independent of the glucose concentration in the medium, the proliferation potential was unchanged at $0.1 \mathrm{mM}$ during $72 \mathrm{~h}$ (1.0-fold with high glucose and 0.97 -fold with normal glucose relative to the control), while reduced proliferation was noted with $1 \mathrm{mM}$ metformin (0.92-fold with high glucose; $\mathrm{P}=0.037)$, followed by a further reduction with increasing metformin concentration $(0.81$-fold at $5 \mathrm{mM}$ 
A

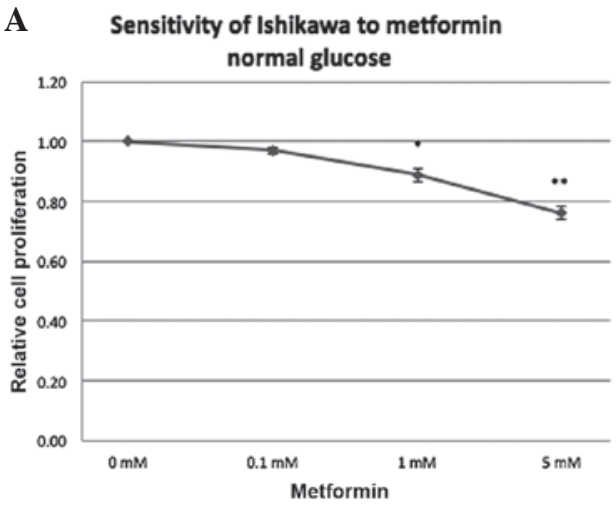

B

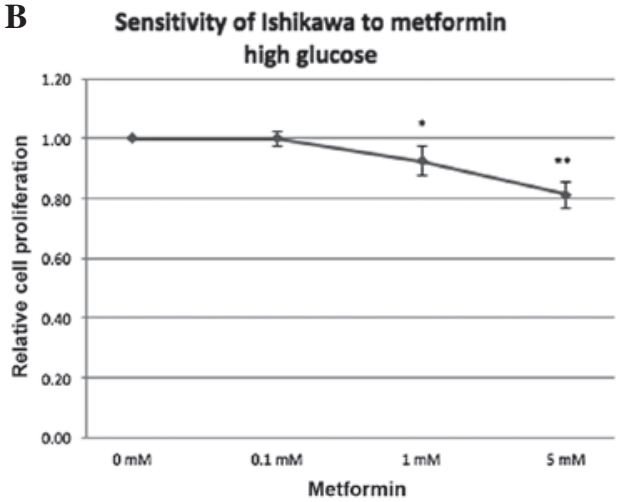

Figure 5. Sensitivity of the Ishikawa cell line to metformin in a (A) high glucose and in a (B) normal glucose environment. The Ishikawa cell line was cultured in the presence of varying concentrations of metformin for $72 \mathrm{~h}$. (A) ${ }^{*} \mathrm{P}=0.037$ and ${ }^{* *} \mathrm{P}=0.002 ;(\mathrm{B}){ }^{*} \mathrm{P}=0.027$ and ${ }^{* *} \mathrm{P}=0.002$. The relative cell proliferation sensitivity of the Ishikawa cell line to metformin was in the range of 1 and $5 \mathrm{mM}$ in the two glucose environments. Mean \pm standard error of the mean.

with high glucose; $\mathrm{P}=0.002)$. In a normal glucose condition, a slightly more pronounced effect was noted compared with that in the high glucose environment $(0.89$-fold for $1 \mathrm{mM}, \mathrm{P}=0.027$; and 0.79 -fold for $5 \mathrm{mM}, \mathrm{P}=0.002$ ).

\section{Discussion}

Considering the increasing level of metformin research in cancer therapy, as well as in patients with type II diabetes mellitus, thus extending its use to the non-diabetic population, the present study investigated the effectiveness of low-dose metformin in EC development and prevention. In order to analyze metformin as a cancer prevention agent and/or cancer progression treatment in endometrial adenocarcinoma type I eEPs and endometrial epithelial cancer cells were exposed to metformin in either a high glucose or normal glucose medium with or without insulin substitution.

Glucose is an essential nutrient that supports cellular energy homeostasis. The normal serum glucose level is usually maintained at $\sim 5.5 \mathrm{mM}$. However, increased blood glucose levels and hyperglycemia contribute to growth and carcinogenesis in EC (26), and act as a critical link between the observed increased cancer risk in patients with type II diabetes (5). Furthermore, in conditions such as PCOS, insulin resistance can be obesity-independent. Despite a normoglycemic state, the associated hyperinsulinemia is believed to be a promoting factor not only for cancer initiation, but also for cancer progression $(7,27)$.

Several studies have suggested that high glucose levels create an optimal environment for cancer cells to exhibit a resistance to metformin (28-30). The current study evaluated the insulin action and the metformin efficiency on the metastatic potential of EC cells when exposed to a high and normal glucose environment. The findings showed that insulin treatment in each glucose condition increased the migration and invasion ability of the endometrial epithelial cancer cells, however, this effect was more pronounced in the high glucose environment. In addition, low-dose metformin effectively attenuated the effects of insulin action in high and normal glucose conditions, leading to a less profound effect. Notably, the results in the normal glucose environment showed a decrease in the ability of the cells to migrate when treated with metformin compared with the control group. However, a significant difference could not be found between the metformin and control groups in a high glucose environment, but compared with the normal glucose environmen, a tendency of cancer cell resistance was present when exposed to high glucose levels. By contrast, insulin alone or in combination with metformin showed no effect on primary eEPs exposed to high glucose conditions with regard to their migration or invasion potential after $16 \mathrm{~h}$. We assume that primary eEPs do not have the metastatic potential observed in cancer cells. Furthermore the short incubation of $16 \mathrm{~h}$ may not be long enough for the insulin to activate the invasion potential of these cells. However, metformin alone was able to reduce the inherent migration capability of the eEPs. These results support the evidence that a high glucose environment interferes in the metformin effect on cancer cells.

To the best of our knowledge, the present study shows for the first time the ability of metformin to inhibit the metastatic potential of endometrial epithelial cancer cells, while the metformin efficiency in the inhibition of migration and invasion has already been reported in a dose-dependent manner in other types of cancer cells, including ovarian (23) and prostate (31) cancer cells, and osteosarcoma (32). Recently, Han et al reported an increased ability of adhesion and invasion in two EC cell lines, suggesting that targeting glucose metabolism may be a promising therapeutic strategy for the treatment of EC (33).

Besides the potential anti-metastatic effect of metformin, several studies have indicated that metformin may be a useful anti-proliferation agent for EC cells. Cantrell et al showed for the first time that metformin potently inhibits growth in two EC cell lines [half maximal inhibitory concentration $\left(\mathrm{IC}_{50}\right)$ of $1 \mathrm{mM}$ metformin] after $72 \mathrm{~h}$ of treatment in a normal glucose environment (17). Takahashi et al demonstrated that after $48 \mathrm{~h}$ of treatment with increasing concentrations of metformin in normal glucose conditions, $\geq 5 \mathrm{mM}$ metformin significantly reduce the number of viable cells ( $\mathrm{IC}_{50}$ of $6.78 \mathrm{mM}$ metformin) (21). Furthermore, the metformin inhibitory proliferation effect has been reported for certain other types of cancer. Wu et al showed that metformin inhibits the proliferation of ovarian cancer cells in a dose- and time-dependent manner in vitro $\left(\mathrm{IC}_{50}\right.$ of $16.67 \mathrm{mM}$ metformin) and in vivo in a nude mouse model (23). Kato et al examined the effects of metformin in prostate cancer cell proliferation using the MTS assay and cell counting. 
The number of viable cells of three prostate cancer cell lines decreased significantly after incubation with metformin $\left(\mathrm{IC}_{50}\right.$ of $5 \mathrm{mM}$ metformin) for $48 \mathrm{~h}$ (31). However, in the present study, in the Ishikawa endometrial epithelial cancer cell line, it was observed that the insulin treatment increased cell proliferation, without any reduction in proliferation by the addition $0.1 \mathrm{mM}$ metformin regardless of the glucose concentration present. This apparent discrepancy may result from the high micromolar metformin concentrations used in the previous studies, which are much greater than the steady-state levels in the patients' plasma. The present study observed the relative cell proliferation sensitivity to metformin in the EC cell line in the range between 1 and $5 \mathrm{mM}$ in each glucose environment, although this was more pronounced in the normal glucose condition. Moreover, these findings were in the presence of estradiol, an important factor in endometrial proliferative disorders, but not used in the published endometrial studies.

In addition, the epidemiological and laboratory studies remain controversial. Numerous details of the action of metformin remain to be identified, and the risk of harm must be considered when designing novel metformin-based therapies. The knowledge gained from the combination of tumor genetics, patient metabolic profiles and the cellular environment will assist in determining the tumor preventative or treatment efficiency of metformin. We expect to improve the understanding of the mechanisms linking glucose metabolism, hyperinsulinemia and metformin treatment with EC development and progression. According to the present findings, it is indicated that metformin at $0.1 \mathrm{mM}$ is not efficient enough to decrease the proliferation in $72 \mathrm{~h}$ of treatment in an EC cell line. However, in this concentration, metformin can inhibit the insulin effect by decreasing the high cellular invasion and migration potential in high and normal glucose environments, demonstrating an anti-metastatic effect of metformin in endometrial epithelial cancer cells. Nevertheless, further investigations are necessary to improve the knowledge of metformin as an effective targeted therapy in cancer, as well as a long term treatment to be efficient in the inhibition of target genes and proteins connected to the development and progression of cancer.

\section{Acknowledgements}

This study was generously supported by National Council for Scientific and Technological Development (CNPq; grant no. 470636/2012-2), Incentive Fund for Research and Events of Clinics Hospital of Porto Alegre (FIPE-HCPA; grant no. 14-0267), Coordination for the Improvement of Higher Education Personnel (CAPES) and the Excellence Initiative from the University of Heidelberg (grant no. 7.013.14).

\section{References}

1. No authors listed: Cancer statistics. JAMA 310: 982, 2013.

2. Garg K and Soslow RA: Endometrial carcinoma in women aged 40 years and younger. Arch Pathol Lab Med 138: 335-342, 2014

3. Clarke CL and Sutherland RL: Progestin regulation of cellular proliferation. Endocr Rev 11: 266-301, 1990.

4. Nead KT, Sharp SJ, Thompson DJ, Painter JN, Savage DB, Semple RK, Barker A; Australian National Endometrial Cancer Study Group (ANECS), Perry JR, Attia J, et al: Evidence of a causal association between insulinemia and endometrial cancer: A mendelian randomization analysis. J Natl Cancer Inst 107: pii: djv178, 2015
5. Szablewski L: Diabetes mellitus: Influences on cancer risk. Diabetes Metab Res Rev 30: 543-553, 2014.

6. SGO Clinical Practice Endometrial Cancer Working Group, Burke WM, Orr J, Leitao M, Salom E, Gehrig P, Olawaiye AB, Brewer M, Boruta D, Villella J, et al: Endometrial cancer: A review and current management strategies: Part I. Gynecol Oncol 134: 385-392, 2014.

7. Mu N, Zhu Y, Wang Y, Zhang H and Xue F: Insulin resistance: A significant risk factor of endometrial cancer. Gynecol Oncol 125: 751-757, 2012.

8. Barone BB, Yeh HC, Snyder CF, Peairs KS, Stein KB, Derr RL, Wolff AC and Brancati FL: Long-term all-cause mortality in cancer patients with preexisting diabetes mellitus: A systematic review and meta-analysis. JAMA 300: 2754-2764, 2008.

9. Friberg E, Orsini N, Mantzoros CS and Wolk A: Diabetes mellitus and risk of endometrial cancer: A meta-analysis. Diabetologia 50: 1365-1374, 2007.

10. Bowers LW, Rossi EL, O'Flanagan CH, deGraffenried LA and Hursting SD: The role of the insulin/IGF system in cancer: Lessons learned from clinical trials and the energy balance-cancer link. Front Endocrinol (Lausanne) 6: 77, 2015.

11. Gallagher EJ and LeRoith D: Obesity and diabetes: The increased risk of cancer and cancer-related mortality. Physiol Rev 95: 727-748, 2015.

12. Shao R, Li X, Feng Y, Lin JF and Billig H: Direct effects of metformin in the endometrium: A hypothetical mechanism for the treatment of women with PCOS and endometrial carcinoma. J Exp Clin Cancer Res 33: 41, 2014.

13. Umene K, Banno K, Kisu I, Yanokura M, Nogami Y, Tsuji K, Masuda K, Ueki A, Kobayashi Y, Yamagami W, et al: New candidate therapeutic agents for endometrial cancer: Potential for clinical practice (review). Oncol Rep 29: 855-860, 2013.

14. Febbraro T, Lengyel E and Romero IL: Old drug, new trick: Repurposing metformin for gynecologic cancers? Gynecol Oncol 135: 614-621, 2014.

15. He H, Ke R, Lin H, Ying Y, Liu D and Luo Z: Metformin, an old drug, brings a new era to cancer therapy. Cancer J 21: 70-74, 2015.

16. Viollet B, Guigas B, Sanz Garcia N, Leclerc J, Foretz M and Andreelli F: Cellular and molecular mechanisms of metformin: An overview. Clin Sci (Lond) 122: 253-270, 2012.

17. Cantrell LA, Zhou C, Mendivil A, Malloy KM, Gehrig PA and Bae-Jump VL: Metformin is a potent inhibitor of endometrial cancer cell proliferation-implications for a novel treatment strategy. Gynecol Oncol 116: 92-98, 2010.

18. Franciosi M, Lucisano G, Lapice E, Strippoli GF, Pellegrini F and Nicolucci A: Metformin therapy and risk of cancer in patients with type 2 diabetes: Systematic review. PLoS One 8: e71583, 2013.

19. Ko EM, Walter P, Jackson A, Clark L, Franasiak J, Bolac C, Havrilesky LJ, Secord AA, Moore DT, Gehrig PA and Bae-Jump V: Metformin is associated with improved survival in endometrial cancer. Gynecol Oncol 132: 438-442, 2014.

20. Tabrizi AD, Melli MS, Foroughi M, Ghojazadeh M and Bidadi S: Antiproliferative effect of metformin on the endometrium-a clinical trial. Asian Pac J Cancer Prev 15: 10067-10070, 2014.

21. Takahashi A, Kimura F, Yamanaka A, Takebayashi A, Kita N, Takahashi K and Murakami T: Metformin impairs growth of endometrial cancer cells via cell cycle arrest and concomitant autophagy and apoptosis. Cancer Cell Int 14: 53, 2014.

22. Sarfstein R, Friedman Y, Attias-Geva Z, Fishman A, Bruchim I and Werner H: Metformin downregulates the insulin/IGF-I signaling pathway and inhibits different uterine serous carcinoma (USC) cells proliferation and migration in p53-dependent or -independent manners. PLoS One 8: e61537, 2013.

23. Wu B, Li S, Sheng L, Zhu J, Gu L, Shen H, La D, Hambly BD, Bao S and Di W: Metformin inhibits the development and metastasis of ovarian cancer. Oncol Rep 28: 903-908, 2012.

24. Chou CC, Lee KH, Lai IL, Wang D, Mo X, Kulp SK, Shapiro CL and Chen CS: AMPK reverses the mesenchymal phenotype of cancer cells by targeting the Akt-MDM2-Foxo3a signaling axis. Cancer Res 74: 4783-4795, 2014.

25. Bao B, Azmi AS, Ali S, Zaiem F and Sarkar FH: Metformin may function as anti-cancer agent via targeting cancer stem cells: The potential biological significance of tumor-associated miRNAs in breast and pancreatic cancers. Ann Transl Med 2: 59, 2014.

26. Lambe M, Wigertz A, Garmo H, Walldius G, Jungner I and Hammar N: Impaired glucose metabolism and diabetes and the risk of breast, endometrial, and ovarian cancer. Cancer Causes Control 22: 1163-1171, 2011.

27. Moran LJ, Hutchison SK, Norman RJ and Teede HJ: Lifestyle changes in women with polycystic ovary syndrome. Cochrane Database Syst Rev: CD007506, 2011. 
28. Sinnett-Smith J, Kisfalvi K, Kui R and Rozengurt E: Metformin inhibition of mTORC1 activation, DNA synthesis and proliferation in pancreatic cancer cells: Dependence on glucose concentration and role of AMPK. Biochem Biophys Res Commun 430: 352-357, 2013.

29. Menendez JA, Oliveras-Ferraros C, Cufí S, Corominas-Faja B, Joven J, Martin-Castillo B and Vazquez-Martin A: Metformin is synthetically lethal with glucose withdrawal in cancer cells. Cell Cycle 11: 2782-2792, 2012.

30. Zhuang Y, Chan DK, Haugrud AB and Miskimins WK: Mechanisms by which low glucose enhances the cytotoxicity of metformin to cancer cells both in vitro and in vivo. PLoS One 9: e108444, 2014
31. Kato H, Sekine Y, Furuya Y, Miyazawa Y, Koike H and Suzuki K: Metformin inhibits the proliferation of human prostate cancer PC-3 cells via the downregulation of insulin-like growth factor 1 receptor. Biochem Biophys Res Commun 461: 115-121, 2015.

32. Chen X, Hu C, Zhang W, Shen Y, Wang J, Hu F and Yu P Metformin inhibits the proliferation, metastasis, and cancer stem-like sphere formation in osteosarcoma MG63 cells in vitro. Tumour Biol 36: 9873-9883, 2015.

33. Han J, Zhang L, Guo H, Wysham WZ, Roque DR, Willson AK, Sheng X, Zhou C and Bae-Jump VL: Glucose promotes cell proliferation, glucose uptake and invasion in endometrial cancer cells via AMPK/mTOR/S6 and MAPK signaling. Gynecol Oncol 138: 668-675, 2015. 